\title{
Reasons and Influences in Music Communication with Traditional Broadcast in the Context of Media Convergence
}

\author{
Runyi Wang ${ }^{1, *}$ \\ ${ }^{1}$ Affiliated High School of Peking University, Beijing, China, 100080 \\ *Corresponding author. Email: 13121059346@163.com
}

\begin{abstract}
Seemingly, Radio is gradually neglected in the current phase of rapid media development, but its development, characteristics and significance are worthy of being discovered and valued. Radio provides the platform as an auditory medium in the process of music dissemination. The development of convergent media has brought challenges to traditional broadcast media, and music broadcasting needs to effectively combine new media, improve, and innovate based on retaining its tradition which allows listeners to have more interest in listening to the program and makes the program more widely known. This paper explores different aspects of music communication, radio development, and media integration to define "communication" and "integration"; at the same time, it uses literature analysis, case studies, and media graphics. Beijing Music Radio can enhance the main purpose of the radio station and the interest of the audience in terms of communication, content, and format.
\end{abstract}

Keywords: convergence media, music radio, reputation, public interest

\section{INTRODUCTION}

Have you ever noticed there are so many choices for people to listen to from the broadcast? Previous researchers discovered such problems of broadcast under convergence media; thus, radio stations need to think about the present situation of their broadcasting program. The "fusion media" is a new type of media that makes full use of media carriers and integrates similar and complementary media such as radio, television, and newspaper. Also, it is committed to creating a new type of media with "integration of resources, content, propaganda, and benefits". The media convergence promoted the innovation of program production formats, accelerated the renewal of program content, and increased several programs to meet the needs of the public. Radio stations have to make some changes in both content and format to adapt to the trend of integrated media in order to develop better and maintain their fame. This research aims to focus on broadcast and find out the reasons and influence behind convergence media which takes Beijing music Broadcasting as an example. The research covers the changes in terms of features, context, and forms of communication. In another dimension, this study also compares not only old media and new media but also contrasts the different characteristics from newspapers, radio, and short videos to online and mobile media. So, there is a question, what innovations should radio stations make in the process of continuous improvement and what impact will it have? Many studies pointed out the hindrances to traditional media in the context of media convergence but did not sort out clearly the advantages and disadvantages of radio itself, not to mention highlighting what kind of content, format, and so on, music communication is using in the medium of radio to make the public more and more popular and the programs more and more famous. Based on the current situation that music broadcasting continues to broaden and innovate, and combined with the two points lacking in the previous studies mentioned above, this study discusses music communication methods and traditional broadcasting together in the context of media convergence. This paper discusses different aspects of broadcasting communication in order to define "communication" and "convergence"; at the same time, this research points out the reasons and influences of the reputation of media from public interest. In addition to analysis, this research uses literature analysis, case 
studies, and graphs from media to draw a conclusion that gives precise answers to the research problem from different perspectives.

\section{ANALYSIS ON BROADCASTING}

\subsection{Development of broadcasting}

International communication is more about communication using mass communication, i.e., communication by a specific social group through print (newspapers, books) or electronic communication (radio, film, television) to the widest possible social audience [8]. To sort out the development of broadcasting from a historical point of view in China, radio communication made radio telegraphy for broadcasting, which at first belonged to military equipment and later was used in the field of business activities. Examples of radio stations formally established for broadcasting news and entertainment can be found in these three stations. In December 1922, American Osborn founded the first radio station in China in Shanghai, which mainly covered international news from the United States and Europe, local news, and entertainment from mainland China. The first Chinese owned the first government-run radio station was the Harbin Government Radio Station, which was established on October 1, 1926. The content broadcast was mainly on March 18, 1927, the first private commercial radio station in China was established. On March 18, 1927, China's first private commercial radio station, Shanghai Xinxin Company Radio, was officially broadcast, mainly broadcasting business quotes, current affairs news, and Chinese music. and Chinese music. All three of these radio stations can be called the "first" in China, although different in nature. Although they were different in nature, they were all news and entertainment in terms of content.

After the introduction of FM radio in 1935, Murrow was assigned as talks director for CBS, then the largest radio network in the United States. But it was not until 1937, when he moved to London to become the network's chief European correspondent, that he became a household name. After assembling the best team of journalists (the famous "Murrow Boys"), he oversaw the creation of foreign news broadcasts it can be seen them today. News dominates most of the radio content, and because radio listeners are often engaged in other activities while listening, radio newscasters' scripts often use a "conversational" style to keep listeners' attention. Not surprisingly, most people listen to radio while driving, in-car radio is very common, and traffic reports grew exponentially in importance to radio news [5].

In-vehicle radio is very capable of reflecting the mobile portability of radio. The emergence of car networking technology makes Bluetooth connection become the standard configuration of the car, car radio is not the only audio media available to the driving public, car networking channels will bring a new experience to users [9].

It's worth noting that in addition to the operation of the station itself, broadcast journalists also play an important role. Broadcast journalism is a profession that requires knowledge, hard work and commitment. As with other media, the advent of digital platforms and the Internet has led to rapid growth in the field in a short period of time, requiring aspiring broadcast journalists to acquire many new skills than their more traditional predecessors would have required [5].

\subsection{Definition and characteristics of broadcasting}

Radio is a means of delivering a large amount of information to a large audience and is the most reliable medium for experiencing global events. It is not only limited to entertainment but can also constrain the work effectively and deliver urgent information. The power of radio broadcasting is to connect people instantly across a wide space and as a broadcasting medium it has helped shape modern society and culture [6]. In developed countries, the broad appeal and rapid popularity of radio allow it to immediately influence public opinion. The conditions and tendencies of the audience influence the broadcast media, so clarifying audience groups is something that the broadcast media has always insisted on [6].

The advantages of radio can be summarized as the ability to quickly disseminate urgent information; mobile portability [9]; time-sensitive and significantly better than television and newspapers; easy and convenient preparation and production of programs; and easier and more convenient to collect, organize, edit, and distribute all kinds of news and information using the Internet compared to the paper media [7]. When it comes to the timeliness and urgency of the dissemination of information, for example, the Wenchuan earthquake at the beginning for the dissemination and diffusion of various information is relying on various larger websites and cell phone messages and other means of real-time dissemination and updates, and then is the radio and television news and other means of dissemination [7].

From the disadvantages of broadcasting, the dissemination of traditional broadcast information is still limited by various constraints such as time, space, and limited expression. Compared with other new media mediums, radio has a small amount of information and a narrow adoption range, which makes it difficult to meet the information needs of the audience, and is limited by the system, program format, and dissemination requirements, so the form of dissemination is very 
single. It is more important as an invisible media with the main factor of sound, which is the only link between broadcast and audience [7].

It is worth noting that radio has been mentioned in Wei's study as a major disadvantage because of its slow update after the content. This study is skeptical of this viewpoint. As one of the traditional media, the content of radio will also be improved with the development of the times to better match the interests and aesthetics of viewers according to the audiences of different channels. As mentioned above, different channels of radio have different audiences, and no matter whether the programs are innovative or not, there will always be a group of loyal old listeners to follow and listen to the programs. When it comes to radio, it is not difficult to think of the $\mathrm{BBC}$, its tradition and classics have always attracted the audience. It can be observed from the fame that people like to listen to the music, drama, etc. broadcast by the BBC. But it is undeniable that people's interest and recognition of the radio format in the context of the new media era will fluctuate.

\subsection{Music Communication in broadcasting}

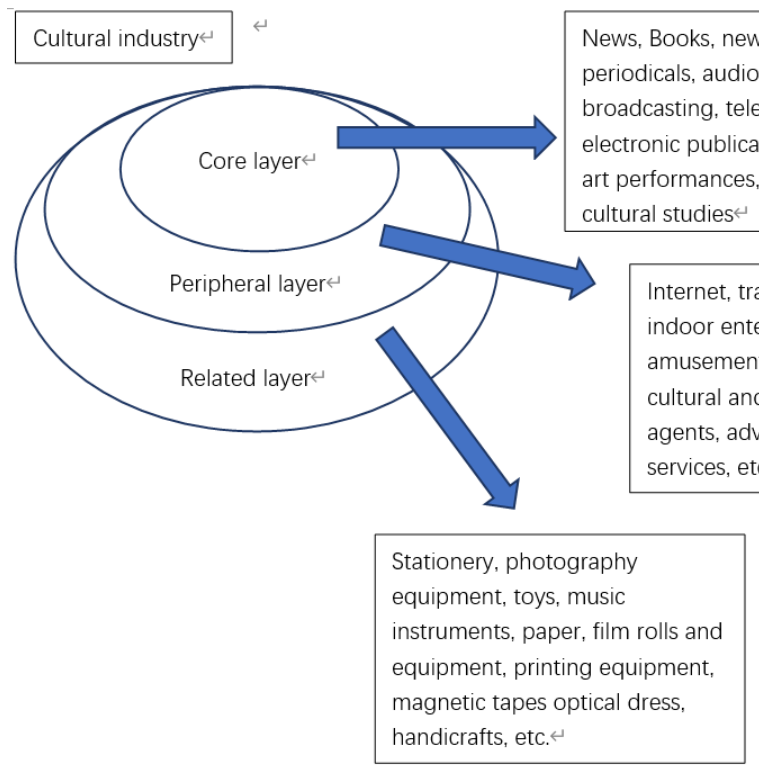

Figure 1. The relationship between media industry and cultural industry

As shown in Figure 1, the relationship of cultural industry and different types of medium. Broadcasting is always in the core layer of culture, the same level as those traditional mediums. Thus, broadcasting has a really important status and role among mediums in the culture industry.

With the emergence of more and more new media, traditional media and new media need to seek effective ways to combine with each other and media integration development.
The combination of recorded music and radio came about after radio became a popular medium for providing live music. In the early 20 th century, sheet music became more popular than recorded music. When the sheet music was widely shared, certain songs gained popular status. In the 1940s and 1950s, popular music was born. Much of the popular music in America was first played by black artists, such as blues, jazz, and rock and roll, all of which originated in black American culture. Throughout the 20th century, different types of music qualified as popular music. Jazz, rock, psychedelic rock, $\mathrm{R} \& \mathrm{~B}$, disco, glam rock, metal, trash rock, rap, electronic dance music, and a wide variety of other forms that defy categorization were all called "pop music". Radio brought advances in sound technology into the home, and the recording industry relied on radio to boost sales so that people could have the music that meant the most to them. In some ways, the extended podcast revived the radio tradition in the distribution of music. The audience for randomly selected podcasts may be small, but overall, there are millions of listeners, and this audio distribution platform continues to grow in young audiences [6].

\subsection{Fusion Media and Broadcasting}

door entertainment

parks, internet cafes,

ents, advertising, exhibition

rvices, etc.

The integration of media has promoted the innovation of program production forms and accelerated the renewal of program contents. In the era of integrated media, radio music programs also have a good prospect of development.

The "integrated media" is a new type of media that makes full use of media carriers, integrates similar and complementary media such as radio, TV, and newspapers, and fully integrates them in terms of human resources, content, and publicity, aiming to create a new 
type of media with "integration of resources, content, propaganda, and interests" [2].

Comparing the characteristics of new media, people can better judge the market of integrated media, which has a very strong initiative and rich content for the audience to choose; is targeted, according to the different nature of the information to the choice of communication channels as well as flexible communication methods. For example, the popularity of short videos in 2017 has created a new language of social interaction and a shift in the interactive way of accessing information [7].

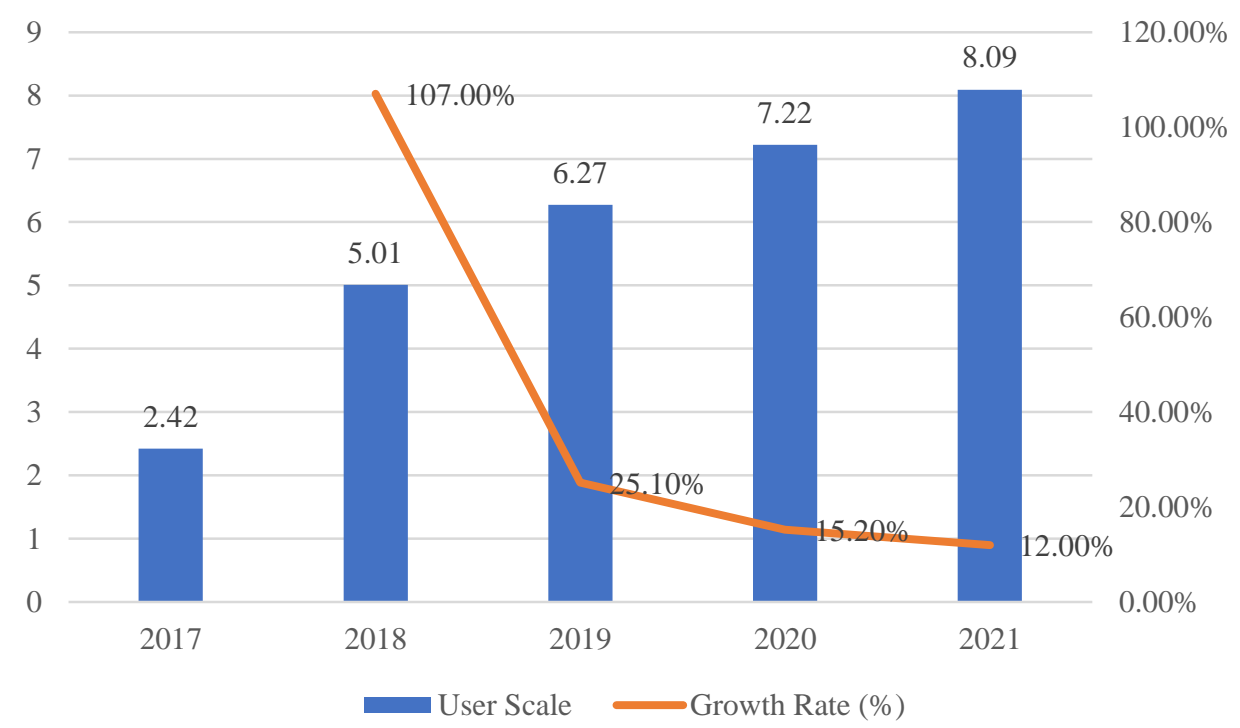

Figure 2. China Short Video User Scale and Forecast, 2017-2021 [8]

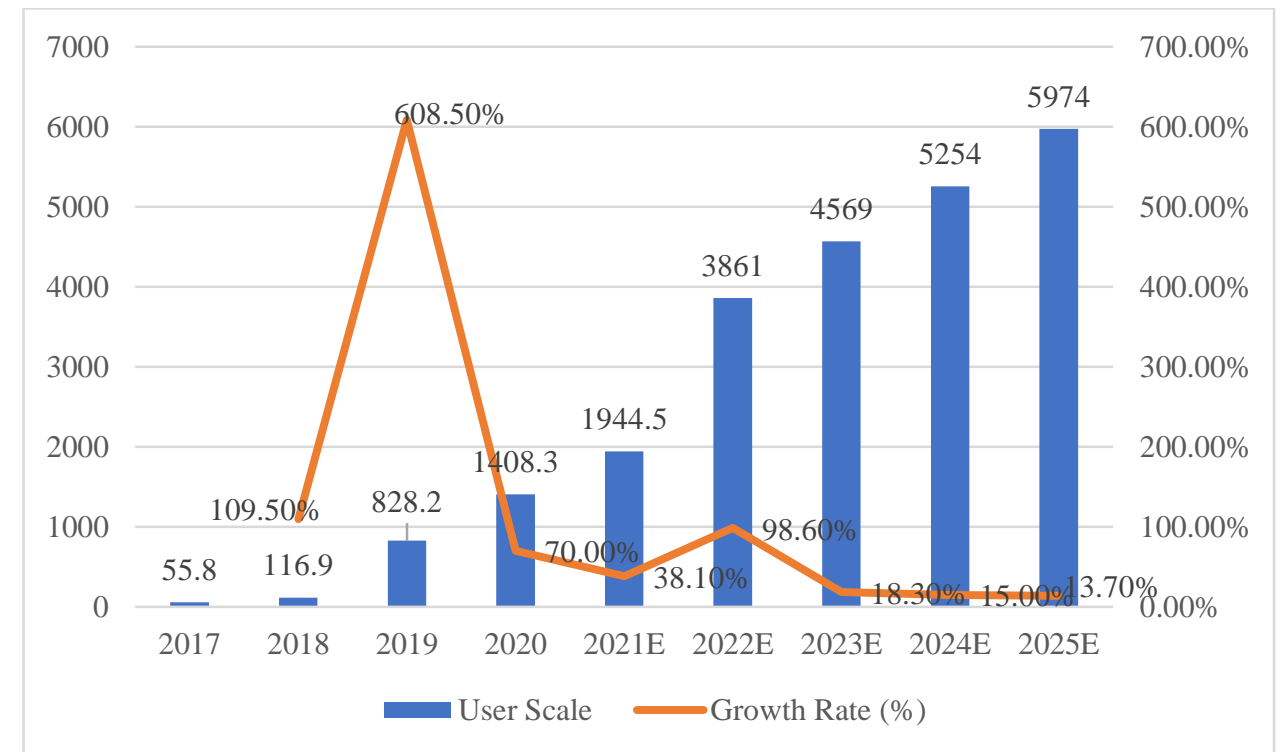

Figure 3. China Short Video Industry Market Size and Forecast 2017-2025E [8]

From Figure 2, it can be seen that the user scale increased progressively from 2017 to 2021 which shows the increasing number of users of short videos in China. This implies the rapid development of new media. For Figure 3 in 2025 China Short Video Industry Market Size and Forecast, the growth of user size and growth rate can also be seen; especially again in 2018 the growth rate was the largest, and then gradually accepted by the market grew steadily.
As mentioned above, music broadcasting is a combination of musical art and radio as a communication medium, resorting to the temporal movement of people's auditory organs. Music is an auditory art and radio is an auditory medium.

Music radio certainly needs to be marketed and penetrated into everyday life for its compliance with the aesthetics and interests of the public, making its influence widespread. 


\section{CASE STUDY: THE CONTENT AND FORM OF BEIJING MUSIC BROADCASTING}

Beijing Music Radio has always had the four principles of popularization: popularization of serious music, artistry of popular music, melodicization of global music, and musicalization of comprehensive programs. Beijing Music Radio (FM97.4), which belongs to Beijing People's Radio, is the longestrunning and most listened to a music radio station in Beijing. The core of Beijing Music Radio is a modern music radio station with a sense of social responsibility, mainly targeting young people and guiding fashion trends. Beijing Music Radio has always relied on the strength of its high-quality programs, famous DJs and the strong resources gathered from the society through the agency of music, record, and performance market advertisements to drive listening and serve listeners wholeheartedly. We believe that in the future fierce competition in the market, we can still win more listeners with our authoritative brand quality, service consciousness, and innovative advantages. From the perspective of communication channels, Beijing Music Radio provides listeners with music and cultural services in all aspects to meet audience needs. Beijing Music Radio combines wireless radio, cable radio, digital radio, official website, official microblog, WeChat public number, classical music fans' "Music Club" and MA Audiophile Club, and other threedimensional communication channels. In addition, Beijing Music Radio is not only limited to various threedimensional communication channels, but also integrates music and media resources to carry out various international broadcasting activities every year, including the Grammy Awards, the All-British Music Awards, the Berlin Forest Concert, the Roskilde Festival in Denmark, the Berlin New Year's Eve Concert, and other music events all over the world. Because music is not only a note to convey ideas and express emotions, but also an important vehicle to express life stories and life feelings, it can leave a deep impression on the audience, thus laying a good foundation for the long and stable development of the program. Therefore, Beijing Music Radio has gradually launched various activities to bring music into people's lives. In recent years, Beijing Music Radio has launched a series of large-scale ground activities such as the "Star DJ Dating Season", "Hundred Words Love Letter" series, "Enjoy the Four Seasons - Beijing Radio Concert", etc. to strengthen the interaction with listeners. In recent years, Beijing Music Radio has launched a series of ground activities such as "Celebrity DJ Dating Season", "100 Love Letters" series, "Enjoying the Seasons - Beijing Radio Concert" and so on, which have strengthened the interaction with listeners and gained wide acclaim from listeners and become more and more famous.
Combined with the background of integrated media development, music radio production should not only give full play to the traditional advantages of low production cost and wide coverage, but also make use of network technology, digital technology, and new media technology to constantly innovate the dissemination of music radio programs. Beijing Music Radio has done a good job of inheriting and innovating music radio programs. It makes full use of the features of high listening quality, low-frequency restriction, and low listening cost of mobile radio, and actively develops mobile music radio programs (Listen FM) to better expand the platform of music radio transmission. In addition, music radio has the characteristics of large resource storage, fast transmission speed, low production cost, and easy reception, etc. It uploads the information of recently broadcast music and establishes a music radio database so that listeners can listen to relevant music programs repeatedly according to their personal preferences.

At the same time, Beijing Music Radio also uses mobile synchronous interactive channels to send the content, text, and pictures of music programs to its subscribers, so as to communicate and interact with them and better improve the dissemination effect of music radio programs.

Specifically, "Afternoon Music Time" is a series of monthly offline concerts conducted by Beijing Music Radio in conjunction with other music resources. The charm of "Afternoon Music Time" is not only the wonderful performance of the artists on stage but also the immersive music experience. At the same time, diversified communication brings music to music lovers. Not only did the audience enjoy the wonderful concerts, but also the live broadcast of Beijing Music Radio, and the addition of online video platforms: Listen FM, BMF Club App, KUK Music K+ Live, Beijing Time, and Central Video, and other major video sites. The combination of live performance and guest interviews, a multi-hyphenate way of viewing the performance with live listening, broadcasting, and webcasting. The dialogue between the professional hosts of the music radio and the performers will also be held throughout the concert, from listening to music to talking about music and tasting music, allowing the audience to discover the fun in melody and feel the charm in culture. The "Afternoon Music Time" series of concerts launched by Music Radio complement the shortcomings of traditional concerts and traditional music radio, and allows concerts to no longer be bound by the restrictions of time and place, and plays a role in dissolving the gap between classical music culture and modern urban life, eliminating the stereotypes of the audience, and bringing the audience closer to the distance between elegant art. 


\section{CONCLUSION}

By discussing and analyzing the meanings and characteristics of music communication, broadcasting, old and new media, and fusion media, this study summarizes and organizes the changes and innovations that need to be done for music broadcasting in the context of fusion media. Music radio should not only differentiate different music genres in terms of content, for example, pop music, classical music, or categorize by theme, but also pay attention to different music audiences, for example, in-car radio, people mostly want to know the traffic situation, so the combination of music and traffic information is a major key point at this time. In addition, music broadcasting should be innovative in terms of format, for example, adding more fun, from the perspective of short videos or using other new media platforms. In addition, music broadcasting can not only be limited to the studio but also add more interactivity and enter people's life.

Only one representative case was selected for the study, therefore, the case study method may be sufficient to illustrate the research problem. The analysis for music radio should be more detailed and convincing, with the development of radio and its characteristics as a background to the presentation. The focus should be on how to effectively reflect the changes that music radio should make in media convergence, and it is also important to clarify its audience if it is to study Beijing music radio. For future research, some of the chart pages in this article show predictions for future data. The author believes that music radio stations are now gradually bringing music and life closer together, thus, they will continue to survive and grow in the future by strengthening the intrinsic value of music, and will focus more on human cultural development, finding points of connection and integration, and eliciting more resonance.

\section{AUTHORS' CONTRIBUTIONS} Wang.

This paper is independently completed by Runyi

\section{ACKNOWLEDGMENTS}

First, I would like to express my deepest gratitude to the teachers and professors of the research project who provided me with valuable guidance and advice while writing this thesis. In addition, I would like to thank my family for their encouragement and support in writing my dissertation, which inspired my initial ideas and allowed me to complete my dissertation successfully.

\section{REFERENCES}

[1] Broadcast \& music industries. RADIO and BROADCAST HISTORY library with thousands of books and magazines. (n.d.). https://worldradiohistory.com/.

[2] Hengyi. How to make good radio music programs in the era of fusion media. Popular Literature and Arts, 2021(11), 113-114. doi:CNKI:SUN:DZLU.0.2021-11-056.

[3] Historical overview of audio-visual communication. (n.d.). https://www.jstor.org/stable/30216718.

[4] Kantilaftis, H. A brief look at the history of broadcast journalism. Film School And Acting School Of New York Film Academy, April 1, 2015. https://www.nyfa.edu/studentresources/history-of-broadcast-journalism/.

[5] Kantilaftis, H., Sugarman, J., \& By. Broadcast journalism. Film School And Acting School Of New York Film Academy, May 24, 2021. https://www.nyfa.edu/student-resources/catbroadcast-journalism/

[6] MAMcIntosh. History and development of radio BROADCASTING, Podcasting, and Superbug Media. Brewminate, March 24, 2021. https://brewminate.com/history-and-developmentof-radio-broadcasting-podcasting-and-superbugmedia/.

[7] Wei, C. Research on the competitive development of broadcasting in the new media environment Master's thesis, Xi'an University of Engineering, 2020

https://kns.cnki.net/KCMS/detail/detail.aspx?dbna me $=$ CMFD202101\&filename $=1020655975 . \mathrm{nh}$

[8] Zhang Guizhen. International Communication and International Relations, Modern Communication Anthology [C] Beijing Broadcasting Institute Press, 2000

[9] Zou Yaju. Innovative research on the development of China's online broadcasting in the context of media convergence, Master's thesis, Lanzhou University, 2018. https://kns.cnki.net/KCMS/detail/detail.aspx?dbna me $=$ CMFD201802\&filename $=1018979229 . \mathrm{nh}$ 